\title{
Repeated Stress Impairs Endocannabinoid Signaling in the Paraventricular Nucleus of the Hypothalamus
}

\author{
Jaclyn I. Wamsteeker, ${ }^{\star}$ J. Brent Kuzmiski, ${ }^{\star}$ and Jaideep S. Bains \\ Hotchkiss Brain Institute and Department of Physiology and Pharmacology, University of Calgary, Calgary, Alberta T2N 4N1, Canada
}

\begin{abstract}
Endocannabinoids (eCBs) are ubiquitous retrograde signaling molecules in the nervous system that are recruited in response to robust neuronal activity or the activation of postsynaptic G-protein-coupled receptors. Physiologically, eCBs have been implicated as important mediators of the stress axis and they may contribute to the rapid feedback inhibition of the hypothalamic-pituitary-adrenal axis (HPA) by circulating corticosteroids (CORTs). Understanding the relationship between stress and eCBs, however, is complicated by observations that $\mathrm{eCB}$ signaling is itself sensitive to stress. The mechanisms that link stress to changes in synaptic eCB signaling and the impact of these changes on CORT-mediated negative feedback have not been resolved. Here, we show that repetitive immobilization stress, in juvenile male rats, causes a functional downregulation of $\mathrm{CB}_{1}$ receptors in the paraventricular nucleus of the hypothalamus (PVN). This loss of $\mathrm{CB}_{1}$ receptor signaling, which requires the activation of genomic glucocorticoid receptors, impairs both activity and receptordependent $\mathrm{eCB}$ signaling at GABA and glutamate synapses on parvocellular neuroendocrine cells in PVN. Our results provide a plausible mechanism for how stress can lead to alterations in CORT-mediated negative feedback and may contribute to the development of plasticity of HPA responses.
\end{abstract}

\section{Introduction}

An acute and adaptive endocrine response to stress, through comprehensive actions of glucocorticoids (GCs), is necessary for survival and, accordingly, is widely conserved across all mammalian species (Pecoraro et al., 2006; Ulrich-Lai and Herman, 2009). The cessation of this response depends, in part, on the central actions of circulating corticosteroids (CORTs) at brain structures such as the hippocampus (Sapolsky et al., 1990; De Kloet et al., 1998), limbic forebrain (Furay et al., 2008), and the hypothalamus (Keller-Wood and Dallman, 1984). Although the negative feedback at higher brain centers is significant, it appears that direct CORT actions on parvocellular neuroendocrine cells (PNCs) in the paraventricular nucleus of the hypothalamus (PVN) may be important for both rapid and sustained termination of the hypothalamic-pituitary-adrenal axis (HPA) response to stress (Dallman, 2005). This feedback, however, may be plastic. For example, robust negative feedback in adult animals remains intact during habituation to predictable stressors (Cole et al., 2000). In contrast, adolescents remain vulnerable to repeated stress (Romeo et al., 2006), which may reflect impaired negative feedback.

In PNCs, the suppression of synaptic glutamate release through the CORT-mediated production of endocannabinoids

\footnotetext{
Received March 1, 2010; revised June 3, 2010; accepted June 23, 2010.

This work was supported by an operating grant from the Canadian Institutes of Health Research (J.S.B.). J.I.W. is supported by the Alberta Heritage Foundation for Medical Research (AHFMR) and is the recipient of the T. Chen Fong Scholarship from the Hotchkiss Brain Institute. J.S.B. is an AHFMR Senior Scholar. We thank the Bains Laboratory for comments on this manuscript and Cheryl Sank for technical assistance.

*J.I.W. and J.B.K. contributed equally to this work.

Correspondence should be addressed to Jaideep S. Bains, University of Calgary, 3330 Hospital Drive NW, Calgary, AB T2N 4N1, Canada. E-mail: jsbains@ucalgary.ca.

DOI:10.1523/JNEUROSCI.1046-10.2010

Copyright $\odot 2010$ the authors $\quad$ 0270-6474/10/3011188-09\$15.00/0
}

(eCBs) (Di et al., 2003) may contribute to this rapid negative feedback. eCBs, in effect, are adaptive signals, and the output and plasticity of the HPA in response to stress are highly sensitive to manipulations that affect eCB signaling (Steiner and Wotjak, 2008). Since chronic stress paradigms have profound effects on eCB signaling in other brain regions including the hippocampus (Hill et al., 2009), amygdala (Patel et al., 2009), and the striatum (Rossi et al., 2008), we hypothesized that repetitive stress would impact eCB signaling in the $\mathrm{PVN}$ and, as a consequence, alter CORT-mediated negative feedback at the level of PNCs.

To examine the effects of repetitive stress on the adaptive nature of eCB signaling, we used an electrophysiological approach in brain slices prepared from adolescent [postnatal day 21 (P21) to P30] rats. We induced eCB production by depolarizing the postsynaptic neuron and examined the effects of this protocol on either glutamate or GABA inputs (Ohno-Shosaku et al., 2001; Wilson and Nicoll, 2001). This approach provides a real-time readout of eCB actions directly at the synaptic $\mathrm{CB}_{1}$ receptors (Regehr et al., 2009). Despite anatomical evidence (Wittmann et al., 2007), the presence of functional $\mathrm{eCB}$ signaling at GABA synapses onto PNCs has been overlooked. Since stress induces a collapse of the chloride ion gradient, rendering GABA either ineffective or excitatory (Hewitt et al., 2009), we reasoned that impairments of eCB signaling at either glutamate or GABA synapses would be consistent with increased excitability in this system. Here, we show that $C B_{1}$ receptors are compromised after $5 \mathrm{~d}$ of repetitive nonhabituating immobilization stress. This results in loss of activity-dependent synaptic inhibition. Finally, inhibition of glutamate release by activation of membrane-bound CORT receptors is also compromised, indicating this mechanism may contribute to HPA escape from inhibition during specific repetitive stress conditions. 


\section{Materials and Methods}

Animals and immobilization stress paradigm. Experiments were performed using male Sprague Dawley rats (postnatal days 21-30). All protocols received approval from the University of Calgary Animal Care Committee in accordance with the guidelines of the Canadian Council on Animal Care. For stress experiments, rats were confined within a Plexiglas cylinder in which they were cervically immobilized to restrict movement for $30 \mathrm{~min}$. Immobilization was initiated at 9:00 A.M. during the light phase for either 1 or 3-10 consecutive days. In some cases, rats were injected intraperitoneally with mifepristone $(25 \mathrm{mg} / \mathrm{kg}$ body weight; Sigma-Aldrich) dissolved in $100 \mu \mathrm{l}$ of DMSO, or DMSO vehicle alone, 10 min before immobilization. Immediately after the last immobilization, rats were anesthetized for slice preparation.

Slice preparation. Experimental animals were anesthetized with sodium pentobarbital $(30-50 \mathrm{mg} / \mathrm{kg})$ and decapitated. Coronal brain slices $(300 \mu \mathrm{m})$ containing the PVN of the hypothalamus were obtained using a vibrating slicer (Leica) while submerged in ice-cold oxygenated slicing solution, consisting of the following (in $\mathrm{mm}$ ): $87 \mathrm{NaCl}, 2.5 \mathrm{KCl}, 0.5$ $\mathrm{CaCl}_{2}, 7 \mathrm{MgCl}_{2}, 25 \mathrm{NaHCO}_{3}, 25$ D-glucose, $1.25 \mathrm{NaH}_{2} \mathrm{PO}_{4}$, and 75 sucrose. Slices were incubated at $32.5^{\circ} \mathrm{C}$ for a minimum of $60 \mathrm{~min}$ in artificial CSF (aCSF) containing the following (in mM): $126 \mathrm{NaCl}, 2.5 \mathrm{KCl}, 26$ $\mathrm{NaHCO}_{3}, 2.5 \mathrm{CaCl}_{2}, 1.5 \mathrm{MgCl}_{2}, 1.25 \mathrm{NaH}_{2} \mathrm{PO}_{4}, 10$ glucose; saturated with $95 \% \mathrm{O}_{2} / 5 \% \mathrm{CO}_{2}$. The preparation of coronal slices from the hippocampus was performed identically to the above description.

Electrophysiology. Hypothalamic slices were transferred to a recording chamber and superfused with $30-32^{\circ} \mathrm{C}$ aCSF at a flow rate of $1-2 \mathrm{ml} /$ min. Slices were visualized using an Olympus BX51WI upright microscope fitted with differential interference contrast optics (Olympus Optical). Whole-cell patch-clamp recordings were obtained from PVN neurons using borosilicate glass microelectrodes with tip resistance between 3 and $7 \mathrm{M} \Omega$. The normal intracellular solution contained the following (in mM): $108 \mathrm{~K}$-gluconate, $2 \mathrm{MgCl}_{2}, 8 \mathrm{Na}$-gluconate, $8 \mathrm{KCl}, 1$ $\mathrm{K}_{2}$-EGTA, $4 \mathrm{~K}_{2}$-ATP, and $0.3 \mathrm{Na}_{3}$-GTP buffered with 10 mM HEPES. In some experiments, BAPTA (10 mm; Sigma-Aldrich) was included in the intracellular solution to buffer postsynaptic calcium changes. For experiments assessing the fast effects of dexamethasone, intracellular concentration of $\mathrm{K}_{2}$-EGTA was reduced to $0.1 \mathrm{~mm}$.

PNCs were identified by their morphology and distinguished from magnocellular and autonomic PVN neurons using electrophysiological characteristics in current-clamp mode (Luther et al., 2002). Recordings were amplified using a Multiclamp 700A amplifier (Molecular Devices), low-pass filtered at $1 \mathrm{kHz}$, and digitized at $10 \mathrm{kHz}$ using the Digidata 1322A (Molecular Devices).

Postsynaptic currents (PSCs) recorded in voltage-clamp mode were evoked using a small diameter $(1 \mu \mathrm{m})$ aCSF-filled glass electrode placed in the neuropil surrounding the cell, to the periventricular aspect (see Fig. 1a). Inhibitory ionotropic $\mathrm{GABA}_{\mathrm{A}}$ receptor evoked IPSCs (eIPSCs) were isolated by blocking AMPA- and kainate receptor-mediated glutamatergic synaptic transmission with 6,7-dinitroquinoxaline-2,3-dione (DNQX) (10 $\mu \mathrm{M}$; Tocris). Conversely, excitatory fast ionotropic AMPA receptor-mediated currents [evoked EPSCs (eEPSCs)] were isolated by addition of picrotoxin (100 $\mu \mathrm{M}$; Sigma-Aldrich) to block $\mathrm{GABA}_{\mathrm{A}}$ receptors. Miniature EPSCs (mEPSCs) were recorded in the presence of tetrodotoxin $(1 \mu \mathrm{M})$. During experiments, access resistance was monitored, and recordings in which access changes did not exceed 15\% were accepted.

Data analysis. Data were recorded (pClamp 9.2; Molecular Devices) and stored on computer for off-line analysis. Synaptic currents were evoked by paired stimulation (at $20 \mathrm{~Hz}$, every $5 \mathrm{~s}$ ) and were analyzed using Clampfit 9.2 (Molecular Devices). Evoked PSC (ePSC) amplitudes were calculated from the baseline (current before the first evoked response) to peak of each evoked response. Mean ePSC amplitudes (in 1 min epochs) were compared by expressing current amplitudes as a percentage of the current amplitudes obtained during the baseline recording period within each cell. Paired-pulse ratio (PPR) was calculated using the ratio of the evoked pair amplitudes (peak 2/peak 1) from 1 min epochs and expressed as percentage of PPR from baseline recording period within each cell. Cells from each group were collected from a minimum of two animals for pharmacology experiments, or a minimum of four for a
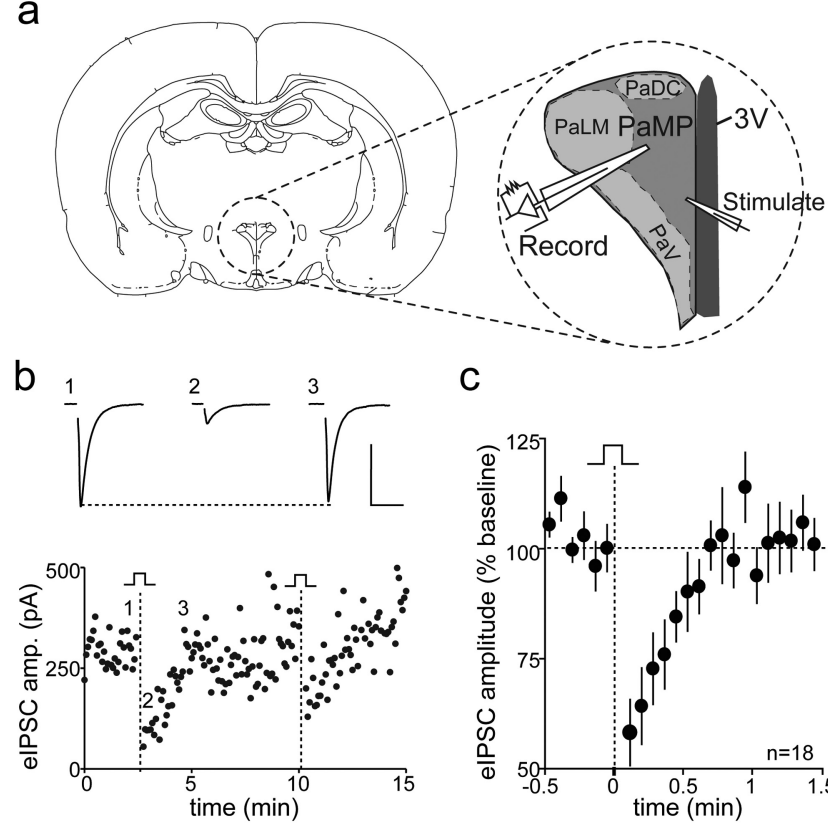

C

d

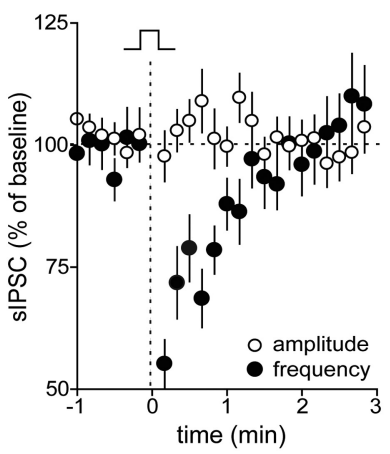

e

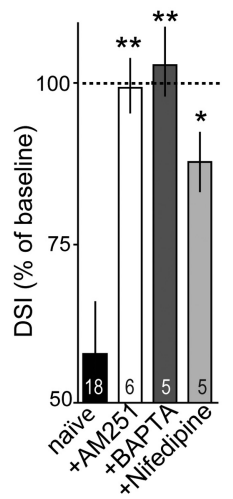

Figure 1. PNCs in the PVN exhibit activity-dependent eCB signaling at GABA synapses. $\boldsymbol{a}$, Schematic of coronal section showing PVN with location of PNCs shown in expanded section. Whole-cell voltage-clamp recordings were made from PNCs. Adapted from Paxinos and Watson (2005). b, Representative recording illustrates time course and magnitude of DSI in response to a voltage step to $+20 \mathrm{mV}$ for $5 \mathrm{~s}$. Traces show elPSC responses (1) during baseline recording, (2) immediately after postsynaptic depolarization, and (3) after 2 min when elPSC amplitude had recovered. Calibration: 200 pA, 20 ms. c, Summary of DSI in all cells tested ( $n=18$ ). $\boldsymbol{d}$, Postsynaptic depolarization transiently depresses frequency but not amplitude of spontaneous IPSCS $(n=18) . \boldsymbol{e}$, Summary graph showing that maximal DSI is significantly inhibited by the $\mathrm{CB}_{1}$ receptor antagonist AM251 (5 $\mu \mathrm{m}$ bath application), inclusion of BAPTA (10 mM) in the intracellular pipette solution, or the L-type calcium channel antagonist nifedipine (10 $\mu \mathrm{m}$ bath application). $N$ for each group is inset within bars (overall ANOVA, $p=0.001, F=7.29$ ). Post hoc versus naive $p$ values are shown as ${ }^{*} p<0.05$ and ${ }^{* *} p<0.01$. Error bars indicate SEM.

stress experiments. Data points are presented as mean \pm SEM. Maximal depolarization-induced suppression of inhibition/excitation (DSI/E) expression within groups was assessed using a one-sample $t$ test, whereas different groups were compared using ANOVA with a post hoc NewmanKeuls test (if overall $p<0.05$ ) or Student's $t$ test (for two groups or paired data). Statistical significance of $t$ test or post hoc comparison is indicated as follows: ${ }^{\star} p<0.05,{ }^{* *} p<0.01$, or ${ }^{\star * *} p<0.001$. Spontaneous currents (sIPSCs and sEPSCs) and miniature currents (mEPSCs; recorded in $1 \mu \mathrm{M}$ tetrodotoxin) representing stochastic transmitter release were analyzed using MiniAnalysis 6.0.3 (Synaptosoft). Event detection was set at three times the baseline noise and confirmed as synaptic events by eye. Running averages of frequency and amplitude were generated using $10 \mathrm{~s}$ bins.

Drugs. Drugs were dissolved into aCSF daily before experiments from frozen aliquots stored at $-20^{\circ} \mathrm{C}$ and added to the bath by perfusion 
pump. Water-soluble dexamethasone (DEX) and tetrodotoxin (TTX) were prepared in distilled water; all others were dissolved in DMSO. DNQX, N-(piperidin-1-yl)-5-(4-iodophonyl)1-(2,4-dichlorophenyl)-4-methyl-1 $H$-pyrazole3-carboxamide (AM251), and ( $R$ )-baclofen were obtained from Tocris Bioscience. Picrotoxin, nifedipine, $(R)-(+)$-[2,3-dihydro-5-methyl-3[(4morpholinyl)methyl] pyrrolo[1,2,3-de]-1, 4-benzoxazinyl]-(1-naphthalenyl)methanone mesylate salt $[(R)-(+)$-WIN55,212-2], corticosterone, and $11 \beta$-(4-dimethylamino) phenyl-17 $\beta$-hydroxy-17-(1-propynyl)estra4,9-dien-3-one (RU-486) were obtained from Sigma-Aldrich. TTX was obtained from Alomone Labs.

\section{Results}

Activity-dependent eCB signaling at GABA synapses on PNCs

In numerous brain regions, DSI and DSE serve as reliable, real-time assays of activity-dependent eCB production (Kreitzer and Regehr, 2001; Ohno-Shosaku et al., 2001; Wilson and Nicoll, 2001). Surprisingly, neither DSI nor DSE has been characterized in PNCs. To determine whether PNCs exhibit DSI, we assessed the effects of depolarizing the postsynaptic neuron from a holding potential of -70 to $+20 \mathrm{mV}$ (5 s) on eIPSCs (Fig. $1 b$ ) (Llano et al., 1991; Pitler and Alger, 1994). This protocol elicited a transient, robust and repeatable decrease in evoked inhibitory current amplitude (eIPSC, $58.2 \pm$ $7.5 \%$ of baseline; $p<0.001 ; n=18$ ) (Fig. $1 c)$. Consistent with previous reports from other brain regions, we found an accompanying decrease in the frequency of sIPSCs $(55.2 \pm 4.9 \%$ of baseline; $p<$ $0.001 ; n=18$ ) (Fig. $1 d$ ) but no changes in sIPSC amplitude $(97.7 \pm 5.1 \%$ of baseline; $p>0.05 ; n=18)$. Thus, depolarization of the postsynaptic neuron causes a transient decrease in the probability of GABA release from presynaptic terminals.

To verify that the DSI reported here is mediated by eCBs, we repeated the depolarizing protocols in the presence of the selective $\mathrm{CB}_{1}$ receptor antagonist, $\mathrm{AM} 251(5 \mu \mathrm{M})$. Under these conditions, DSI was completely abolished (eIPSC, $99.5 \pm 4.3 \%$ of baseline, $p>0.05, n=6$; $p<0.01$ vs naive) (Fig. $1 e$ ), indicating that $\mathrm{CB}_{1}$ receptors are necessary for the short-term synaptic depression. To determine whether activity-dependent production of eCBs also requires a rise in postsynaptic calcium, we conducted experiments in which we included the calcium chelator BAPTA $(10 \mathrm{~mm})$ in the patch pipette. In these recordings, postsynaptic depolarization had no effect on eIPSC amplitude (103.4 $\pm 5.4 \%$ of baseline, $p>0.05, n=5$; $p<0.01$ vs naive). Next, we tested whether L-type voltage-gated calcium channels contribute to the production of eCBs. Application of the L-type calcium channel antagonist, nifedipine $(10 \mu \mathrm{M})$, before depolarizing the postsynaptic membrane significantly, but incompletely, attenuated expression of DSI (eIPSC, $88.1 \pm 4.6 \%$ of baseline, $p<0.05, n=5$; $p<0.05$ vs naive). Importantly, nifedipine had no effect on basal b
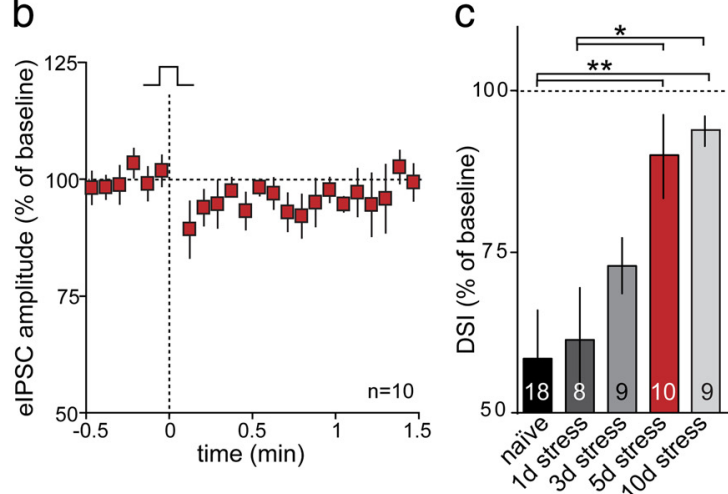

Figure 2. Loss of activity-dependent eCB signaling after repeated immobilization stress. $\boldsymbol{a}$, Sample data from a single cell in animals subjected to 30 min of immobilization stress repeated once daily for $5 \mathrm{~d}(n=10)$. c, Summary bar graph of maximal DS in naive animals and animals subjected to $1,3,5$, or $10 \mathrm{~d}$ of immobilization stress. $N$ for each group is inset within bars (overall

a 5 d stress +3 d recovery

b

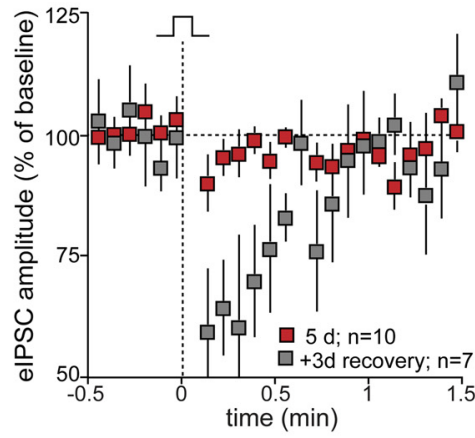

C

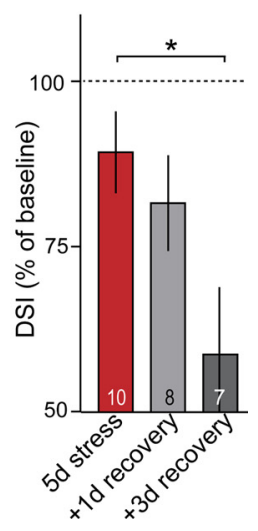

Figure 3. Time course of recovery of eCB signaling after 5 d immobilization stress. $\boldsymbol{a}$, Sample data from an individual cell in an for comparison. c, Bar graph of maximal DSI from animals allowed to recover from $5 \mathrm{~d}$ stress for 1 or $3 \mathrm{~d}$ compared with $5 \mathrm{~d}$ stress data to show that DSI is fully recovered by $3 \mathrm{~d}$ after stress. N for each group is inset within bars (overall ANOVA, $p=0.02$, $F=4.22$ ). Post hoc comparisons are shown as ${ }^{*} p<0.05$. Error bars indicate SEM.

synaptic transmission, indicating that L-type calcium channels do not participate in neurotransmitter release onto PNCs. Together, these observations are consistent with the hypothesis that the opening of voltage-gated L-type calcium channels and the accompanying rise in postsynaptic calcium are necessary for the suppression of GABA transmission by eCBs in response to postsynaptic depolarization.

\section{Loss of eCB-mediated synaptic inhibition at GABA synapses} after repeated immobilization stress

HPA responses exhibit remarkable plasticity in response to chronic homotypic and heterotypic stress paradigms (Pecoraro et al., 2006). Although these may result from changes in eCB signaling at higher brain centers, the importance of eCBs in directly affecting synaptic function in the PVN (Di et al., 2003) led us to investigate the effects of stress on retrograde eCB signaling in PNCs. We conducted experiments in which animals were subjected to either 1, 3, or $5 \mathrm{~d}$ of $30 \mathrm{~min}$ immobilization stress. This homotypic stress paradigm, which causes robust corticotropinreleasing hormone $(\mathrm{CRH}), \mathrm{ACTH}$, and CORT production, fails 
a 100nM CORT incubation b
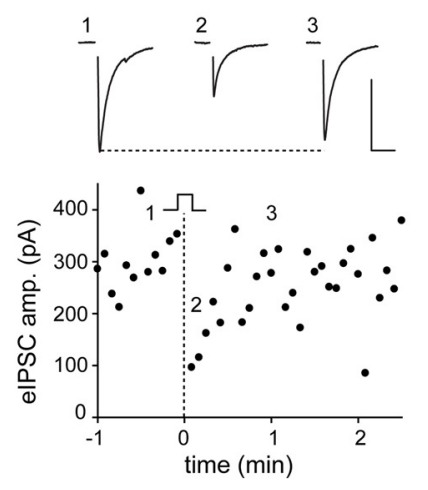

d $\quad 5$ d stress + in vivo RU-486
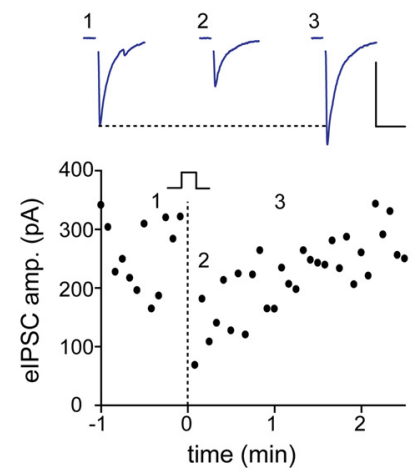

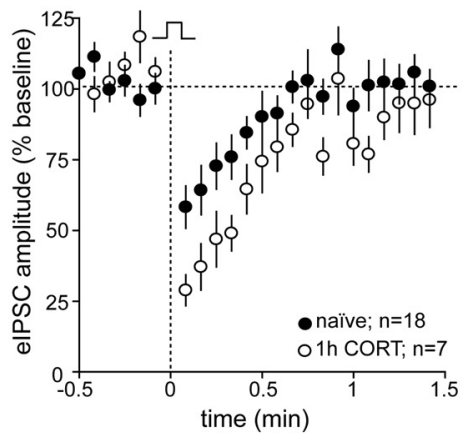

e

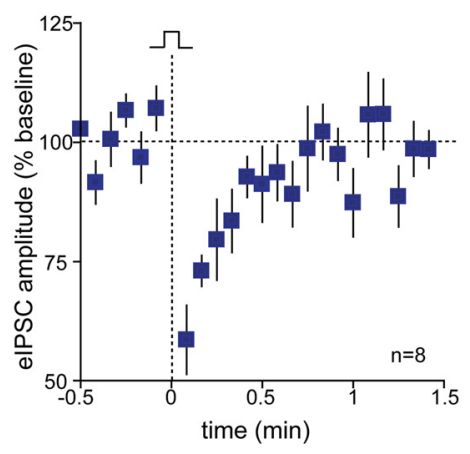

Figure 4. Loss of eCB signaling requires CORT activation of genomic GC receptors. $\boldsymbol{a}$, Sample cell from a slice incubated in CORT (100 nm) for $1 \mathrm{~h}$ shows robust DSI. Calibration: 200 pA, 20 ms. $\boldsymbol{b}$, Average of DSI data from slices incubated for $1 \mathrm{~h}$ in CORT $(n=7)$ with naive data replotted for comparison. $c$, Summary graph comparing maximal DSI from naive slices with those incubated in CORT for 1 and $3 \mathrm{~h}$ (overall ANOVA, $p=0.049, F=3.34$ ). $\boldsymbol{d}$, Representative data from one cell from an animal injected with RU-486 ( $25 \mathrm{mg} / \mathrm{kg}$ body weight, i.p.) $10 \mathrm{~min}$ before each episode of immobilization stress for $5 \mathrm{~d}$ (blue). Calibration: 150 pA, $20 \mathrm{~ms} . \boldsymbol{e}$, Averaged data from $n=8$ cells demonstrate that DSI is present in animals administered RU- 486 before $5 \mathrm{~d}$ stress. $f$, Summary graph comparing maximal DSI of $5 \mathrm{~d}$ stress to $5 \mathrm{~d}$ stress with DMSO vehicle or the GC receptor antagonist RU-486 injected before stress (overall ANOVA, $p=0.006, F=4.90$ ). $N$ for each group is inset within bars. Post hoc comparisons are shown as ${ }^{*} p<0.05$. Error bars indicate SEM.

to habituate with repetition in adolescent rats (Romeo et al., 2006). This is in contrast to demonstrated habituation in adults (Grissom and Bhatnagar, 2009). ELISA measurement of blood CORT levels at 30 min showed similar levels of stress hormone in rats stressed for the first or fifth time (data not shown). A single episode of immobilization stress had no effect on DSI (eIPSC: $56.9 \pm 7.5 \%$ of baseline, $p<0.01, n=8$; $p>0.05$ vs naive) (Fig. $2 c$ ). After $3 \mathrm{~d}$ of immobilization stress, there was a trend toward reduced eCB signaling, although this was not significantly different from naive animals (eIPSC, $72.6 \pm 4.3 \%$ of baseline, $p<0.01, n=9 ; p=0.079$ vs naive). After $5 \mathrm{~d}$ of repeated immobilization stress, however, we observed an attenuation of DSI (eIPSC, $89.7 \pm 2.5 \%$ of baseline, $p<0.05, n=10 ; p<$ 0.05 vs naive DSI) (Fig. $2 a-c$ ).

Although $5 \mathrm{~d}$ of immobilization stress significantly reduced the expression of DSI in comparison with naive animals, it did not abolish DSI completely ( $p<0.01$ vs baseline). Consequently, we performed additional experiments on animals stressed for $10 \mathrm{~d}$. In these animals, DSI was significantly reduced compared with naive animals (eIPSC, $95.3 \pm 4.1 \%$ of baseline, $n=9 ; p<0.01$ vs naive) (Fig. $2 c$ ). There was no reduction in eIPSC amplitude compared with baseline $(p>0.05)$. These observations indicate that there is a progressive loss of eCB-mediated retrograde inhibition
C

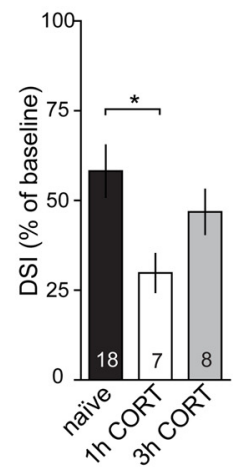

f

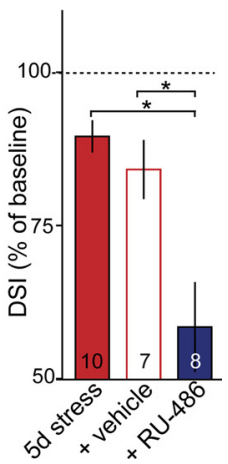

at GABA synapses on PNCs in response to repeated exposure to a stressor.

Next, we investigated whether the loss of eCB signaling at GABA synapses after repetitive immobilization stress was reversible by allowing animals to recover for various time periods after $5 \mathrm{~d}$ stress. One day of recovery had no effect on DSI when compared with $5 \mathrm{~d}$ stress animals (eIPSC, $84.6 \pm 5.5 \%$ of baseline, $p<0.05, n=8$; NS vs $5 \mathrm{~d}$ stress) (Fig. $3 c$ ). After $3 \mathrm{~d}$ of recovery, however, DSI was observed at a level that was similar to that reported above in naive animals (eIPSC, $58.7 \pm$ $10.0 \%$ of baseline, $p<0.01, n=7 ; p<$ 0.05 vs 5 d stress) (Fig. $3 a-c$ ).

\section{Genomic GC receptors are necessary for repeated stress-induced loss of eCB signaling}

CORT acts on putative membranebound GC receptors in PVN to produce eCBs (Di et al., 2003). This raises the possibility that stress-induced increases in circulating CORT may cause agonistinduced downregulation of $\mathrm{CB}_{1}$ receptors. To directly examine these nongenomic effects of CORT in extinguishing retrograde signaling, we incubated hypothalamic slices for either 1 or $3 \mathrm{~h}$ in aCSF containing $100 \mathrm{~nm}$ CORT (Fig. $4 a-c$ ). In contrast to repeated stress, $1 \mathrm{~h}$ incubation in CORT enhanced, rather than inhibited, DSI (eIPSC, $28.8 \pm$ $5.3 \%$ of baseline, $p<0.001, n=7 ; p<0.05$ vs naive) (Fig. $4 c$ ), whereas $3 \mathrm{~h}$ incubation in CORT had no effect on DSI (eIPSC, $46.8 \pm$ $6.2 \%$ of baseline; $p<0.001 ; n=8$ ).

CORT actions at the genomic GC receptor may contribute to reduced $\mathrm{CB}_{1}$ receptor expression or function (Rossi et al., 2008). To test this hypothesis, animals were injected either with the GC receptor antagonist, $\mathrm{RU}-486$ ( $25 \mathrm{mg} / \mathrm{kg}$ body weight, i.p.), or vehicle (DMSO) $10 \mathrm{~min}$ before each of the five immobilization episodes. Pretreatment with RU-486 preserved DSI, revealing a level of synaptic inhibition that was comparable with that observed in naive animals (eIPSC, $58.6 \pm 4.2 \%$ of baseline, $p<$ $0.001, n=8 ; p<0.05$ vs $5 \mathrm{~d}$ stress, vs $5 \mathrm{~d}$ stress plus vehicle) (Fig. $4 d-f$ ). In contrast, vehicle-treated, $5 \mathrm{~d}$ stress animals displayed a loss of DSI that was similar to nonvehicle-injected 5-d-stressed rats (eIPSC, $84.3 \pm 4.7 \%$ of baseline, $p<0.05, n=7$; NS vs $5 \mathrm{~d}$ stress).

Together, these results demonstrate that CORT, through intracellular GC receptor activation, is responsible for the loss of eCB signaling after repetitive stress.

\section{Repeated-immobilization stress induces a loss of signaling at presynaptic $\mathrm{CB}_{1}$ receptors}

The loss of eCB signaling after repetitive exposure to stress may be attributable to CORT-dependent impairments of eCB synthesis in the postsynaptic cell, changes in enzymatic breakdown, or a decrease in presynaptic $\mathrm{CB}_{1}$ receptor function. $\mathrm{CB}_{1}$ receptors in other brain regions are remarkably labile in response to various stress paradigms (Rossi et al., 2008; Hill et al., 2009; Patel et al., 
a

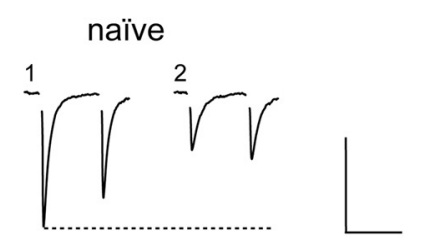

b

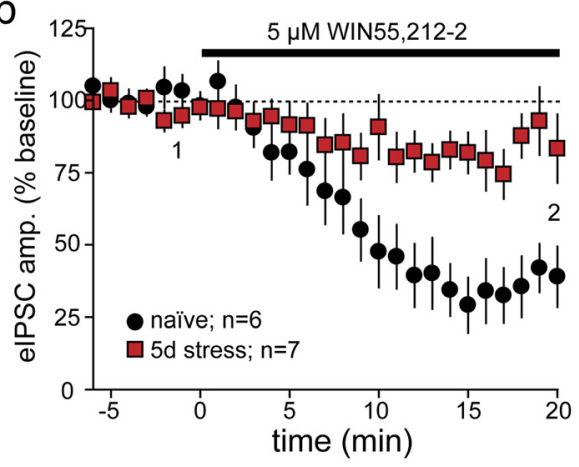

5 day stress

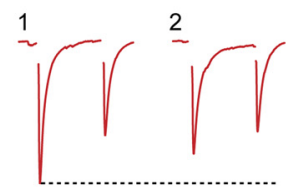

C

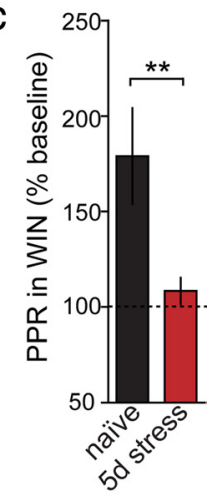

d

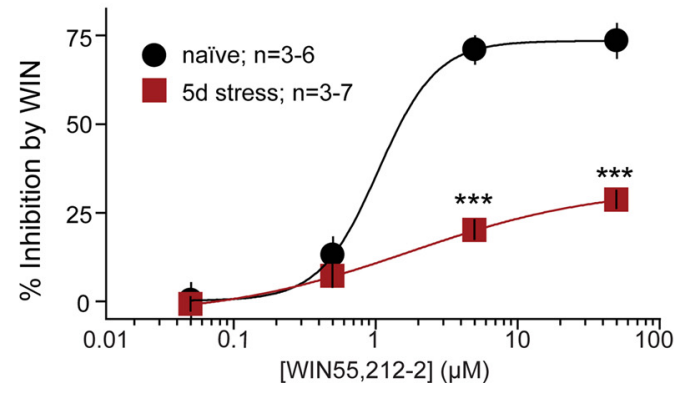

Figure 5. Presynaptic $\mathrm{CB}_{1}$ receptor function is compromised after $5 \mathrm{~d}$ immobilization stress. $\boldsymbol{a}$, Sample data showing paired-pulse elPSC recordings during (1) baseline and (2) $20 \mathrm{~min}$ after application of the $\mathrm{CB}_{1}$ receptor agonist WIN55,212-2 (WIN) $(5 \mu \mathrm{M})$ in cells from a naive animal (black) and an animal subjected to $5 \mathrm{~d}$ of immobilization stress (red). Calibration: $150 \mathrm{pA}, 50 \mathrm{~ms}$. $\boldsymbol{b}$, Averaged data showing the efficacy of WIN in suppressing eIPSC amplitude in cells from naive $(n=6)$ versus $5 \mathrm{~d}$ stress $(n=7)$ animals. c, Summary graph comparing WIN-mediated change in PPR after 20 min between treatment groups. ${ }^{* *} p<0.01, t$ test. $\boldsymbol{d}$, Dose-response of WIN inhibition of elPSC amplitude in naive and stressed animals. Post hoc comparisons are shown as ${ }^{* * *} p<0.001$ (two-way ANOVA). Error bars indicate SEM.

2009), suggesting similar changes may occur in the PVN. To address this question directly, we used the exogenous $\mathrm{CB}_{1}$ receptor agonist, WIN55,212-2 (WIN) $(5 \mu \mathrm{M})$, to assay the functionality of presynaptic $\mathrm{CB}_{1}$ receptors. In naive rats, WIN reduced eIPSC amplitude to $29.1 \pm 9.5 \%$ of baseline $(p<0.001 ; n=6)$ (Fig. $5 a, b$ ) and increased the PPR to $179.0 \pm 25.2 \%$ of baseline (raw PPR baseline vs WIN, $p<0.05$, paired $t$ test) (Fig. $5 c$ ), illustrating that $C_{1}$ receptor activation decreases $G A B A$ release probability. After $5 \mathrm{~d}$ of immobilization stress, the effectiveness of WIN was significantly reduced; eIPSC amplitude was $81.8 \pm$ $7.0 \%$ of baseline ( $p>0.05, n=7 ; p<0.01$ vs naive, $t$ test) (Fig. $5 a, b)$. Under these conditions, the WIN-induced change in PPR was significantly reduced compared with naive animals (108.3 \pm $7.0 \%$ of baseline; $p<0.05$ vs naive change in PPR) (Fig. $5 c$ ). An assay of GABA synapse sensitivity to varying concentrations of WIN shows that, although suppression of eIPSCs by lower doses $(50,500 \mathrm{~nm})$ was comparable between naive and stressed rats, the responsiveness of $5 \mathrm{~d}$ stress rat synapses was reduced at supramaximal doses ( $5 \mu \mathrm{M} ; p<0.001,50 \mu \mathrm{M} ; p<0.001, n=5$ naive, $n=$ 4 stress) (Fig. $5 d$ ) These data support the hypothesis that the loss of eCB signaling after repetitive immobilization stress is attributable to a functional downregulation of presynaptic $\mathrm{CB}_{1}$ receptors.
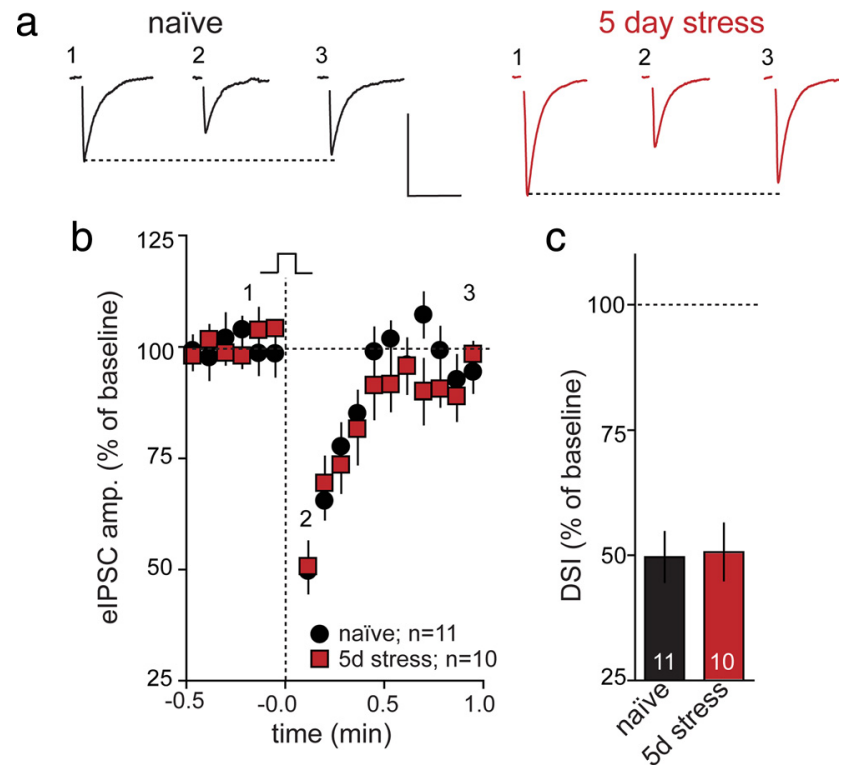

Figure 6. DSI in hippocampal CA1 pyramidal neurons is unaffected by $5 \mathrm{~d}$ immobilization stress. $\boldsymbol{a}$, Representative elPSCs from single hippocampal CA1 pyramidal neurons (1) during baseline, (2) immediately after depolarization, and (3) 1 min after depolarization recorded in naive (black) and $5 \mathrm{~d}$ stressed (red) animals. Calibration: 300 pA, 50 ms. $\boldsymbol{b}$, Averaged data from naive $(n=11)$ and $5 \mathrm{~d}$ stress $(n=10)$ animals showing that depolarization to $+20 \mathrm{mV}$ for $5 \mathrm{~s}$ similarly elicits a robust depression of elPSC amplitude between treatment groups. c, Summary graph shows that maximal DSI in CA1 neurons is not significantly different in naive versus $5 \mathrm{~d}$ stressed animals. N for each group is inset within bars ( $p>0.05, t$ test). Error bars indicate SEM.

Chronic administration of CORT has also been reported to downregulate $\mathrm{G} \alpha_{\mathrm{i} \alpha 2}$-protein subunits in hypothalamic tissue (David et al., 2009). Since presynaptic $\mathrm{CB}_{1}$ receptors are coupled to $\mathrm{G} \alpha_{\mathrm{i}}$ signaling, we asked whether the loss of eCB signaling may reflect a general loss of $\mathrm{G} \alpha_{\mathrm{i}}$ signaling. To test this hypothesis, we activated the $\mathrm{G} \alpha_{\mathrm{i}}$-coupled $\mathrm{GABA}_{\mathrm{B}}$ receptor with its exogenous ligand, baclofen $(30 \mu \mathrm{M})$. Under control conditions, baclofen depressed eIPSC amplitude $(28.2 \pm 8.6 \%$ of baseline; $p<0.001$; $n=9$ ). This inhibition was not significantly affected by $5 \mathrm{~d}$ immobilization stress $(23.9 \pm 6.1 \%$ of baseline, $p<0.001, n=6$; NS vs naive animals). Importantly, a significant increase in PPR was also observed (190 $\pm 30.6 \%$ of baseline; $p<0.05$ ). Collectively, these observations indicate that repeated stress specifically impairs $\mathrm{CB}_{1}$ receptors at synapses onto $\mathrm{PNCs}$ and that alternate mechanisms that may modify release probability at GABA synapses after stress (Verkuyl et al., 2005) are unlikely to be responsible for the attenuation of $\mathrm{CB}_{1}$ receptor signaling.

\section{Repeated stress does not impair DSI in hippocampus}

Since both chronic stress and CORT downregulate $\mathrm{CB}_{1}$ receptors in the adult rodent hippocampus (Hill et al., 2008, 2009), a structure implicated in the termination of stress-initiated HPA responses (Sapolsky et al., 1989), we investigated whether $5 \mathrm{~d}$ immobilization stress might also impact DSI in the hippocampus. Using the same protocol as in PNCs, we induced robust DSI in CA1 pyramidal neurons (eIPSC, $49.7 \pm 5.0 \%$ of baseline; $p<$ $0.001 ; n=11$ ) (Fig. $6 a-c$ ). The magnitude of DSI in CA1 neurons, however, was unaltered by $5 \mathrm{~d}$ immobilization stress ( $50.7 \pm 5.6 \%$ of baseline, $p<0.001, n=10$; NS vs naive). These data suggest that synapses onto PVN neurons exhibit greater sensitivity to stress-induced changes in retrograde eCB signaling than GABA synapses onto hippocampal CA1 pyramidal neurons. 


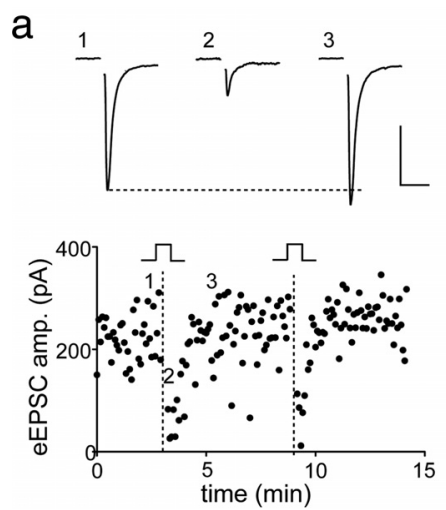

b
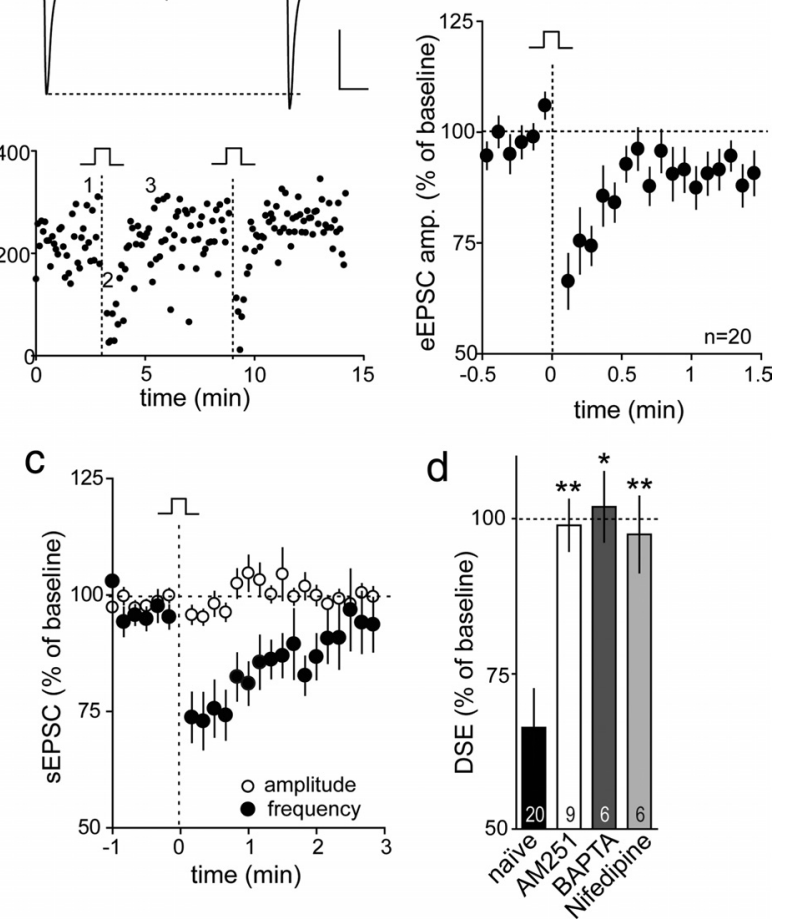

Figure 7. PNCs exhibit activity-dependent eCB signaling at glutamate synapses. $\boldsymbol{a}$, Representative single eEPSC recording illustrates the time course of DSE. Traces show eEPSC responses in (1) baseline and at (2) $0 \mathrm{~min}$ and (3) $2 \mathrm{~min}$ after depolarization to $+20 \mathrm{mV}$ for $5 \mathrm{~s}$. Calibration: $100 \mathrm{pA}, 10 \mathrm{~ms} . \boldsymbol{b}$, Averaged data from $n=20$ cells show the time course of DSE. c, Postsynaptic depolarization transiently depresses frequency but not amplitude of spontaneous EPSCS $(n=$ 20). $\boldsymbol{d}$, Summary graph of maximal DSE showing that DSE in naive slices is significantly reduced in the presence of $\mathrm{CB}_{1}$ receptor antagonist AM251 (5 $\mu \mathrm{m}$ bath), inclusion of BAPTA (10 mM intrapipette), or the L-type calcium channel antagonist nifedipine (10 $\mu \mathrm{m}$ bath) (overall ANOVA, $p=0.0006, F=7.24) . N$ for each group is inset within bars. Post hoc versus naive $p$ values are shown as ${ }^{*} p<0.05$ and ${ }^{* *} p<0.01$. Error bars indicate SEM.

\section{Loss of eCB-mediated inhibition of glutamate synapses after repeated immobilization stress}

Since eCB signaling specifically at glutamatergic synapses has been implicated in the fast negative feedback of the HPA in response to stress (Di et al., 2003), we also examined the effects of immobilization stress on DSE. Similar to the effect on eIPSCs, postsynaptic depolarization resulted in a robust and repeatable depression of eEPSCs $(66.3 \pm 6.2 \%$ of baseline; $p<0.001 ; n=$ 20) (Fig. $7 a, b, d)$. There was also a depression in the frequency, but not the amplitude of sEPSCs (frequency, $73.7 \pm 5.4 \%$ of baseline; $p<0.001 ; n=20$ ) (Fig. $7 c$ ), consistent with a decrease in the probability of glutamate release from the presynaptic terminal. DSE was blocked by either the $C_{1}$ receptor antagonist AM251 (98 $\pm 4.1 \%$ of baseline, $p>0.05, n=9 ; p<0.01$ vs naive) (Fig. $7 d$ ), chelating intracellular calcium with BAPTA (101.9 \pm 5.6 of baseline, $p>0.05, n=6$; $p<0.05$ vs naive), or inhibition of L-type voltage-gated calcium channels with nifedipine (97.5 \pm $6.1 \%$ of baseline, $p>0.05, n=6 ; p<0.01$ vs naive).

Next, we investigated whether eCB signaling at glutamate synapses was sensitive to repeated immobilization stress. Consistent with the effects at GABA synapses, when animals were subjected to $1 \mathrm{~d}$ (eEPSC, $77.6 \pm 6.1 \%$ of baseline, $p<0.001, n=8 ; p>0.05$ vs naive) or $3 \mathrm{~d}$ (eEPSC, $82.1 \pm 7.1 \%$ of baseline; $p<0.05 ; n=9$ ) (Fig. 8c) of immobilization stress DSE persisted. Although not significant, there was a trend toward reduced DSE after $3 \mathrm{~d}$ ( $p=$
0.078 vs naive). After $5 \mathrm{~d}$ of immobilization stress, however, there was a complete loss of DSE at glutamatergic synapses (eEPSC, $102.0 \pm 2.8 \%$ of baseline, $p>0.05, n=10 ; p<0.001$ vs naive) (Fig. $8 a-c$ ).

Since our observations at GABA synapses indicate that repeated stress causes a functional downregulation of $\mathrm{CB}_{1}$ receptors on GABAergic terminals, we also tested whether the loss of DSE was attributable to reduced $\mathrm{CB}_{1}$ receptor function. In naive animals, application of the $\mathrm{CB}_{1}$ receptor agonist WIN reduced eEPSC amplitude ( $44.6 \pm 10.7 \%$ of baseline; $p<0.001 ; n=6)$ (Fig. $8 d$ ). After $5 \mathrm{~d}$ of immobilization stress, the effects of WIN at glutamate synapses were significantly reduced (eEPSC, $88.3 \pm$ $6.5 \%$ of baseline amplitude, $p>0.05, n=6$; $p<0.01$ vs naive) (Fig. $8 d$ ). Finally, to determine whether GC receptors were also involved in the functional downregulation of $\mathrm{CB}_{1}$ receptors on glutamate synapses, we injected the GC receptor antagonist RU486 before each episode of immobilization stress. Pretreatment with RU-486 prevented the loss of DSE after $5 \mathrm{~d}$ stress (eEPSC, $70.1 \pm 3.4 \%$ of baseline, $p<0.001, n=8$; $p<0.05$ vs $5 \mathrm{~d}$ stress, $5 \mathrm{~d}$ stress plus vehicle) (Fig. $8 e, f$ ), whereas DSE was abolished in vehicle-treated 5-d-stressed animals (eEPSC, $92.4 \pm 7.0 \%$ of baseline, $p>0.05, n=12 ; p<0.01$ vs $5 \mathrm{~d}$ stress). Collectively, these data support the hypothesis that repeated exposure to stress impairs eCB signaling at glutamate and GABA synapses. In both cases, this impairment is attributable to a GC receptor-mediated, functional downregulation of presynaptic $\mathrm{CB}_{1}$ receptors.

\section{Repeated stress impairs eCB signaling after activation of postsynaptic G-protein-coupled receptors}

Activity is only one trigger for the production of eCBs. Activation of postsynaptic G-protein-coupled receptors (GPCRs) can also drive eCB production via $\mathrm{G} \alpha_{\mathrm{q}}$-coupled recruitment of the PLC $\beta$ (phospholipase $\mathrm{C} \beta$ ) pathway (Maejima et al., 2001; Varma et al., 2001). GPCR-driven eCB production exists in multiple forms in the PVN (Di et al., 2003; Oliet et al., 2007; Kuzmiski et al., 2009). The eCB-mediated suppression of glutamate release onto PVN neurons via the activation of membrane-bound GC receptors and a $\mathrm{G} \alpha_{\mathrm{s}}$-dependent pathway (Di et al., 2009) has been implicated as a possible mechanism for the fast negative feedback of the HPA in response to stress (Dallman, 2005). Since we established above that $5 \mathrm{~d}$ immobilization stress downregulates presynaptic $\mathrm{CB}_{1}$ receptors, we hypothesized that this should manifest as a loss of CORT-mediated fast feedback inhibition at glutamate synapses. Consistent with previous studies (Di et al., 2003), application of dexamethasone $(5 \mu \mathrm{M})$ resulted in a rapid and persistent decrease in the frequency of mEPSCs $(70.5 \pm 6.4 \%$ of baseline; $p<0.001 ; n=6$ ) (Fig. $9 a-c$ ) but had no effect on mEPSC amplitude (data not shown). This decrease was blocked by the $\mathrm{CB}_{1}$ receptor antagonist AM251 $(5 \mu \mathrm{M} ; 97.4 \pm 3.0 \%$ of baseline; $p>0.05 ; n=5 ; p<0.01$ vs naive). After $5 \mathrm{~d}$ stress, however, dexamethasone failed to depress the frequency of mEPSCs (104.6 $\pm 5.3 \%$ of baseline, $p>0.05, n=8 ; p<0.001$ vs naive). These data support the hypothesis that rapid CORT-mediated fast feedback via eCB production is extinguished after $5 \mathrm{~d}$ stress.

\section{Discussion}

In this study, we demonstrate that repetitive immobilization stress results in the loss of eCB-mediated retrograde signaling in PNCs of the PVN of prepubescent rats. This plasticity, which is attributable to a CORT-mediated functional downregulation of presynaptic $\mathrm{CB}_{1}$ receptors, provides a first demonstration that retrograde $\mathrm{CB}$ signaling in the hypothalamic command neurons responsible for regulating HPA output, is labile, but reversible. 
This loss of $\mathrm{CB}_{1}$ receptor function has important implications for CORT-mediated feedback inhibition of the HPA.

Previous reports have demonstrated that eCBs, produced in response to activationofpostsynapticCORT-sensitive, membrane-bound GPCRs, depress glutamate release onto PNCs (Di et al., 2003). We augment these findings by demonstrating that these cells also produce eCBs as a retrograde signal in response to postsynaptic depolarization. Furthermore, we demonstrate that eCBs act as retrograde messengers at both glutamate and GABA synapses onto PNCs in PVN, a finding that supports ultrastructural evidence of $\mathrm{CB}_{1}$ immunoreactivity at both glutamateand GABA-containing terminals (Wittmann et al., 2007). That transmission at both glutamate and GABA synapses is suppressed by PNC depolarization appears, at first, to be counterproductive in assembling an appropriate stress-induced hormonal response at the synaptic level. This, however, may not be the case as acute immobilization stress disrupts intracellular chloride homeostasis and results in conditional GABA-mediated excitations in PNCs (Hewitt et al., 2009). This highlights the importance of context in interpreting the role of eCB signaling. Under a condition in which both GABA and glutamate are excitatory, activitydependent suppression of both glutamatergic and GABAergic synapses may represent a critical mechanism for curtailing HPA output after stress exposure. One unexpected observation that provides additional support for eCBs in mediating feedback inhibition is the acute enhancement of DSI by in vitro $1 \mathrm{~h}$ incubation with CORT. This would curtail GABAdriven excitations and quench HPA activity. Previous work, using GC receptor ligands, has failed to demonstrate rapid $\mathrm{eCB}$ production at GABA synapses in these cells (Verkuyl et al., 2005). A likely interpretation of these observations is that membrane-bound GC receptors are distributed primarily at glutamate synapses. Since GABA and glutamate synapses are intermingled on PNCs (Decavel and van den Pol, 1992), this indicates that rapid GC-mediated production of eCBs exhibits spatial precision. It is also plausible that enhancement of DSI by CORT after $1 \mathrm{~h}$ of exposure represents a priming of eCB signaling through the membrane-bound CORT GPCR. Together, these findings support the hypothesis that the "outcome" of functional loss of signaling at the $\mathrm{CB}_{1}$ receptor after repeated stress would be to impair the ability of PNCs to dampen their own activity by removing retrograde inhibition.

From a mechanistic standpoint, our results demonstrate that CORT is necessary for the loss of eCB signaling after repetitive stress but argues against a role for agonist-induced desensitization of the $\mathrm{CB}_{1}$ receptor or a direct interaction between membrane-bound $\mathrm{GC}$ and $\mathrm{CB}_{1}$ receptors. Instead, our results point to a role for intracellular GC receptor activation and a b

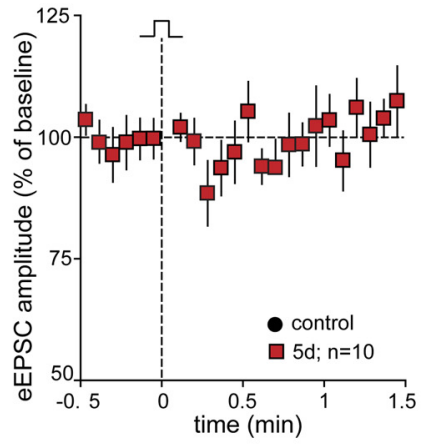

C

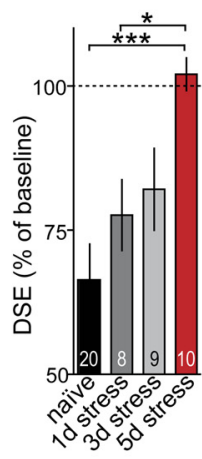

e

$5 \mathrm{~d}$ stress + in vivo RU-486
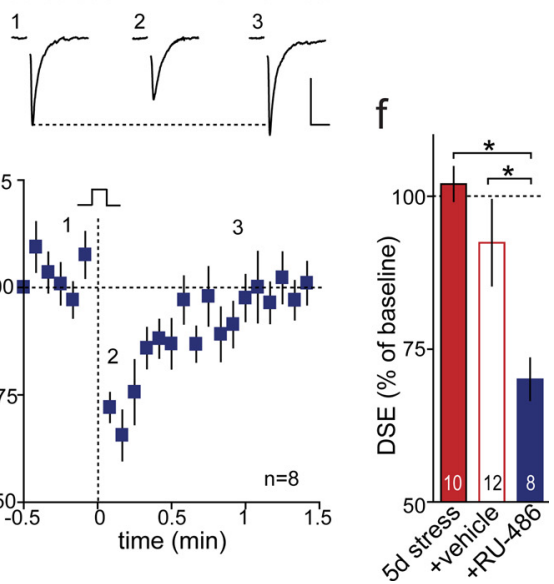

Figure 8. Genomic $\mathrm{GC}$ receptor activation during repeated immobilization stress compromises $\mathrm{CB}_{1}$ receptor function at glutamanses. $\boldsymbol{a}$, Sample data from a single cell in a $5 \mathrm{~d}$ stress animal showing eEPSC amplitude (1) before, (2) immediately after, Calibration: 100 pA, 50 ms. e, Representative traces from one cell in an animal injected with RU-486 ( 25 mg/kg body weight, i.p.) min before each episode of immobilization stress for $5 \mathrm{~d}$ and averaged data from RU-486-treated animals ( $n=8$; blue) eceptor antagonist RU-486 injected 10 min before each immobilization episode (overall ANOVA, $p=0.0004, F=7.21$ ). $N$ for each group is inset within bars. Post hoc comparisons are shown as ${ }^{*} p<0.05$ and ${ }^{* * *} p<0.001$. Error bars indicate SEM.

genomic signaling cascade leading to the loss of responsive synaptic $\mathrm{CB}_{1}$ receptors in neurons that synapse onto PNCs. Previous studies have demonstrated that chronic administration of $\mathrm{CB}$ receptor agonists can downregulate $\mathrm{CB}_{1}$ receptor density (Breivogel et al., 1999 ) and that activity-dependent $\mathrm{eCB}$-mediated suppression of inhibition in the hippocampus is abolished by administration of THC ( $\Delta$ 9-tetrahydrocannabinol) (Mato et al., 2004). Since CORT drives eCB production in PNCs (Di et al., 2003), repetitive stress, in which circulating CORT is elevated daily, could lead to agonist-induced desensitization of $\mathrm{CB}_{1}$ receptors. Although agonist-dependent receptor downregulation is possible, our data argue that the most plausible scenario is via CORT altering the transcription of the $\mathrm{CB}_{1}$ receptor itself (Mailleux and Vanderhaeghen, 1993), or some component that maintains $\mathrm{CB}_{1}$ receptors at presynaptic terminals. This idea is supported by the observation that the GC receptor antagonist RU-486 does not inhibit the putative membrane-associated GC receptor responsible for the production of eCBs that is proposed as a mechanism for fast negative-feedback regulation of the HPA (Di et al., 2003). 
a

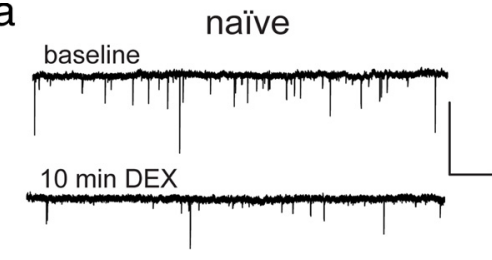

\section{b}

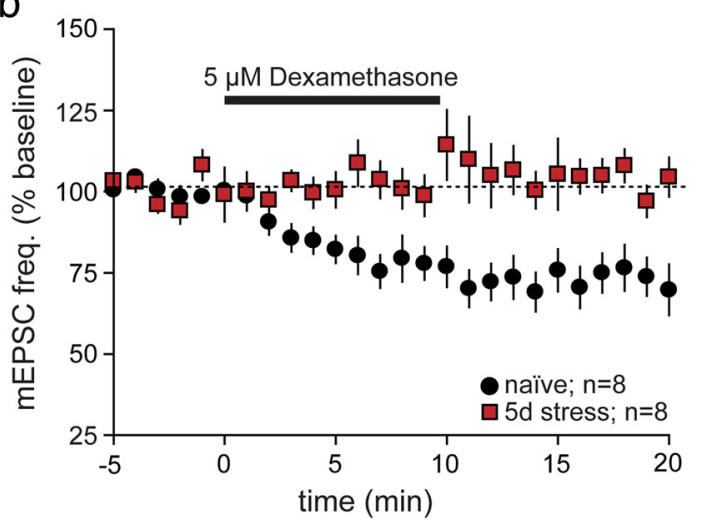

5 day stress

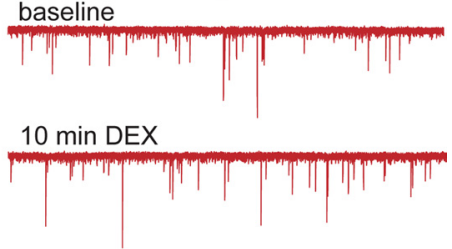

C

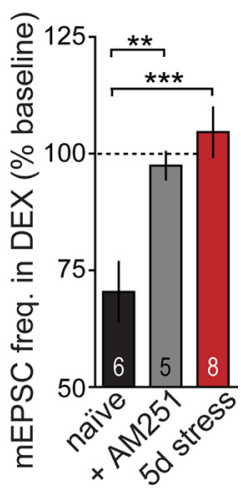

Figure 9. Loss of GPCR-dependent production of eCBs after repeated immobilization stress. $\boldsymbol{a}$, Suppression of quantal glutamate release in response to a DEX-responsive putative GPCR is reduced by $5 \mathrm{~d}$ stress. Representative recordings of mEPSCs (recorded in $1 \mu \mathrm{m}$ tetrodotoxin) from naive (black) and $5 \mathrm{~d}$ stress (red) animals before (baseline) and after ( $10 \mathrm{~min}$ ) bath perfusion of $5 \mu$ m water-soluble DEX. Calibration: $50 \mathrm{pA}, 1 \mathrm{~s}$. $\boldsymbol{b}$, Averaged data of normalized mEPSC frequency from naive $(n=8)$ and $5 \mathrm{~d}$ stress $(n=8)$ animals showing loss of DEX effects on $m E$ EPSC frequency. $c$, Summary graph of mEPSC frequency (as percentage of baseline) after $10 \mathrm{~min}$ of DEX in naive and $5 \mathrm{~d}$ stress animals, and in naive slices bathed in AM251 (5 $\mu \mathrm{M}$ ) (overall ANOVA, $p=0.0009, F=11.34)$. N for each group is inset within bars. Post hoc comparisons are shown as a* $p<0.01$ and ${ }^{* * *} p<0.001$. Error bars indicate SEM.

Previous studies indicate that chronic psychosocial stress exposure in adult mice similarly results in reduced $\mathrm{CB}_{1}$ receptor function at inhibitory synapses in the striatum through the genomic GC receptor (Rossi et al., 2008). This reduced sensitivity to exogenous agonist may also occur at inhibitory synapses in the basolateral amygdala (BLA) after habituating homotypic restraint (Patel et al., 2009). Although this may be taken to suggest that GC receptor activity exerts negative transcriptional control over the $\mathrm{CB}_{1}$ receptor, generalizations about uniform effects of stress on brain $\mathrm{eCB}$ synaptic function might be overly simplistic. Indeed, activity-dependent eCB signaling (DSI) in the BLA is enhanced despite reduced agonist efficacy.

The presence of functional eCB signaling at large has been mechanistically implicated in the extinction of conditioned stress responses (Marsicano et al., 2002) and the habituation of HPA responses resulting from homotypic stress (Patel and Hillard, 2008). Our observations are mostly consistent with this idea but also provide new perspectives. We have used a vulnerable, adolescent phenotype (P21-P30 rats), taking advantage of a specific developmental window in which the brain appears uniquely sensitive to stress (Lupien et al., 2009). Unlike adult rodents, stress-induced increases in CORT do not display habituation in prepubescent rats and instead show heightened peak hormonal responses to subsequent stress along with enhanced CRH production in PNCs (Romeo et al., 2006). Here, we show that a failure of hormonal adaptation to a repeated stress challenge is accompanied by loss of eCB signaling at the final common synapses of central stress circuits. Interestingly, it appears that the effects of adolescent stress extend into adulthood, resulting in increased anxiety behavior (Avital and Richter-Levin, 2005) and increased stress sensitivity (Isgor et al., 2004), indicating that these augmented levels of GCs early in life may have profound consequences on the maturing limbic brain.

We conclude that repeated stress in the adolescent rat reduces the ability of PNCs to autoregulate their synapses and compromises the ability of CORT feedback to globally dampen glutamatergic drive to these cells. This might allow for tight coupling between relayed limbic synaptic input and HPA output in response to subsequent stress and reduce the ability of GCs to restrain stress-induced hormonal release. Furthermore, our study supports the idea that eCB signaling modulates stress responses and is, in turn modulated by them. Finally, we provide a potential mechanism by which plasticity of the hormonal stress response can evolve through state-dependent changes in synaptic signaling.

\section{References}

Avital A, Richter-Levin G (2005) Exposure to juvenile stress exacerbates the behavioural consequences of exposure to stress in the adult rat. Int J Neuropsychopharmacol 8:163-173.

Breivogel CS, Childers SR, Deadwyler SA, Hampson RE, Vogt LJ, Sim-Selley LJ (1999) Chronic delta9-tetrahydrocannabinol treatment produces a time-dependent loss of cannabinoid receptors and cannabinoid receptor-activated $G$ proteins in rat brain. J Neurochem 73:2447-2459.

Cole MA, Kalman BA, Pace TW, Topczewski F, Lowrey MJ, Spencer RL (2000) Selective blockade of the mineralocorticoid receptor impairs hypothalamic-pituitary-adrenal axis expression of habituation. J Neuroendocrinol 12:1034-1042.

Dallman MF (2005) Fast glucocorticoid actions on brain: back to the future. Front Neuroendocrinol 26:103-108.

David DJ, Samuels BA, Rainer Q, Wang JW, Marsteller D, Mendez I, Drew M, Craig DA, Guiard BP, Guilloux JP, Artymyshyn RP, Gardier AM, Gerald C, Antonijevic IA, Leonardo ED, Hen R (2009) Neurogenesisdependent and -independent effects of fluoxetine in an animal model of anxiety/depression. Neuron 62:479-493.

Decavel C, van den Pol AN (1992) Converging GABA- and glutamateimmunoreactive axons make synaptic contact with identified hypothalamic neurosecretory neurons. J Comp Neurol 316:104-116.

De Kloet ER, Vreugdenhil E, Oitzl MS, Joëls M (1998) Brain corticosteroid receptor balance in health and disease. Endocr Rev 19:269-301.

Di S, Malcher-Lopes R, Halmos KC, Tasker JG (2003) Nongenomic glucocorticoid inhibition via endocannabinoid release in the hypothalamus: a fast feedback mechanism. J Neurosci 23:4850-4857.

Di S, Maxson MM, Franco A, Tasker JG (2009) Glucocorticoids regulate glutamate and GABA synapse-specific retrograde transmission via divergent nongenomic signaling pathways. J Neurosci 29:393-401.

Furay AR, Bruestle AE, Herman JP (2008) The role of the forebrain glucocorticoid receptor in acute and chronic stress. Endocrinology 149:5482-5490.

Grissom N, Bhatnagar S (2009) Habituation to repeated stress: get used to it. Neurobiol Learn Mem 92:215-224.

Hewitt SA, Wamsteeker JI, Kurz EU, Bains JS (2009) Altered chloride homeostasis removes synaptic inhibitory constraint of the stress axis. Nat Neurosci 12:438-443.

Hill MN, Carrier EJ, Ho WS, Shi L, Patel S, Gorzalka BB, Hillard CJ (2008) Prolonged glucocorticoid treatment decreases cannabinoid CB1 receptor density in the hippocampus. Hippocampus 18:221-226.

Hill MN, Hunter RG, McEwen BS (2009) Chronic stress differentially regulates cannabinoid CB1 receptor binding in distinct hippocampal subfields. Eur J Pharmacol 614:66-69. 
Isgor C, Kabbaj M, Akil H, Watson SJ (2004) Delayed effects of chronic variable stress during peripubertal-juvenile period on hippocampal morphology and on cognitive and stress axis functions in rats. Hippocampus 14:636-648.

Keller-Wood ME, Dallman MF (1984) Corticosteroid inhibition of ACTH secretion. Endocr Rev 5:1-24.

Kreitzer AC, Regehr WG (2001) Retrograde inhibition of presynaptic calcium influx by endogenous cannabinoids at excitatory synapses onto Purkinje cells. Neuron 29:717-727.

Kuzmiski JB, Pittman QJ, Bains JS (2009) Metaplasticity of hypothalamic synapses following in vivo challenge. Neuron 62:839-849.

Llano I, Leresche N, Marty A (1991) Calcium entry increases the sensitivity of cerebellar Purkinje cells to applied GABA and decreases inhibitory synaptic currents. Neuron 6:565-574.

Lupien SJ, McEwen BS, Gunnar MR, Heim C (2009) Effects of stress throughout the lifespan on the brain, behaviour and cognition. Nat Rev Neurosci 10:434-445.

Luther JA, Daftary SS, Boudaba C, Gould GC, Halmos KC, Tasker JG (2002) Neurosecretory and non-neurosecretory parvocellular neurones of the hypothalamic paraventricular nucleus express distinct electrophysiological properties. J Neuroendocrinol 14:929-932.

Maejima T, Hashimoto K, Yoshida T, Aiba A, Kano M (2001) Presynaptic inhibition caused by retrograde signal from metabotropic glutamate to cannabinoid receptors. Neuron 31:463-475.

Mailleux P, Vanderhaeghen JJ (1993) Glucocorticoid regulation of cannabinoid receptor messenger RNA levels in the rat caudate-putamen. An in situ hybridization study. Neurosci Lett 156:51-53.

Marsicano G, Wotjak CT, Azad SC, Bisogno T, Rammes G, Cascio MG, Hermann H, Tang J, Hofmann C, Zieglgänsberger W, Di Marzo V, Lutz B (2002) The endogenous cannabinoid system controls extinction of aversive memories. Nature 418:530-534.

Mato S, Chevaleyre V, Robbe D, Pazos A, Castillo PE, Manzoni OJ (2004) A single in vivo exposure to $\triangle 9 \mathrm{THC}$ blocks endocannabinoid-mediated synaptic plasticity. Nat Neurosci 7:585-586.

Ohno-Shosaku T, Maejima T, Kano M (2001) Endogenous cannabinoids mediate retrograde signals from depolarized postsynaptic neurons to presynaptic terminals. Neuron 29:729-738.

Oliet SH, Baimoukhametova DV, Piet R, Bains JS (2007) Retrograde regulation of GABA transmission by the tonic release of oxytocin and endocannabinoids governs postsynaptic firing. J Neurosci 27:1325-1333.

Patel S, Hillard CJ (2008) Adaptations in endocannabinoid signaling in response to repeated homotypic stress: a novel mechanism for stress habituation. Eur J Neurosci 27:2821-2829.

Patel S, Kingsley PJ, Mackie K, Marnett LJ, Winder DG (2009) Repeated homotypic stress elevates 2-arachidonoylglycerol levels and enhances short-term endocannabinoid signaling at inhibitory synapses in basolateral amygdala. Neuropsychopharmacology 34:2699-2709.

Paxinos G, Watson C (2005) The rat brain in stereotaxic coordinates. San Diego, CA: Elsevier Academic.

Pecoraro N, Dallman MF, Warne JP, Ginsberg AB, Laugero KD, la Fleur SE, Houshyar H, Gomez F, Bhargava A, Akana SF (2006) From Malthus to motive: how the HPA axis engineers the phenotype, yoking needs to wants. Prog Neurobiol 79:247-340.

Pitler TA, Alger BE (1994) Depolarization-induced suppression of GABAergic inhibition in rat hippocampal pyramidal cells: $\mathrm{G}$ protein involvement in a presynaptic mechanism. Neuron 13:1447-1455.

Regehr WG, Carey MR, Best AR (2009) Activity-dependent regulation of synapses by retrograde messengers. Neuron 63:154-170.

Romeo RD, Bellani R, Karatsoreos IN, Chhua N, Vernov M, Conrad CD, McEwen BS (2006) Stress history and pubertal development interact to shape hypothalamic-pituitary-adrenal axis plasticity. Endocrinology 147:1664-1674.

Rossi S, De Chiara V, Musella A, Kusayanagi H, Mataluni G, Bernardi G, Usiello A, Centonze D (2008) Chronic psychoemotional stress impairs cannabinoid-receptor-mediated control of GABA transmission in the striatum. J Neurosci 28:7284-7292.

Sapolsky RM, Armanini MP, Sutton SW, Plotsky PM (1989) Elevation of hypophysial portal concentrations of adrenocorticotropin secretagogues after fornix transection. Endocrinology 125:2881-2887.

Sapolsky RM, Armanini MP, Packan DR, Sutton SW, Plotsky PM (1990) Glucocorticoid feedback inhibition of adrenocorticotropic hormone secretagogue release: relationship to corticosteroid receptor occupancy in various limbic sites. Neuroendocrinology 51:328-336.

Steiner MA, Wotjak CT (2008) Role of the endocannabinoid system in regulation of the hypothalamic-pituitary-adrenocortical axis. Prog Brain Res 170:397-432.

Ulrich-Lai YM, Herman JP (2009) Neural regulation of endocrine and autonomic stress responses. Nat Rev Neurosci 10:397-409.

Varma N, Carlson GC, Ledent C, Alger BE (2001) Metabotropic glutamate receptors drive the endocannabinoid system in hippocampus. J Neurosci 21:RC188(1-5).

Verkuyl JM, Karst H, Joëls M (2005) GABAergic transmission in the rat paraventricular nucleus of the hypothalamus is suppressed by corticosterone and stress. Eur J Neurosci 21:113-121.

Wilson RI, Nicoll RA (2001) Endogenous cannabinoids mediate retrograde signalling at hippocampal synapses. Nature 410:588-592.

Wittmann G, Deli L, Kalló I, Hrabovszky E, Watanabe M, Liposits Z, Fekete C (2007) Distribution of type 1 cannabinoid receptor (CB1)-immunoreactive axons in the mouse hypothalamus. J Comp Neurol 503:270279. 